\title{
Learning Interoperability in Emerging Supply Networks
}

\author{
Georg Weichhart, Matthias Neubauer, and Christian Stary \\ Johannes Kepler University Linz, Department of Business Information \\ Systems - Communications Engineering, Freistädterstr. 315 \\ A- 4040 Linz, Austria \\ \{Georg.Weichhart, Matthias.Neubauer, Christian.Stary\}@jku.at
}

\begin{abstract}
Automotive suppliers are moving from supply-chain process design to dynamic socio-economic networking when speeding up innovation cycles to improve their competitiveness. In this way cross-organizational learning processes are triggered. Enabling team formation for collaboratively developing innovative products and services requires interoperability on several levels and in different flavors. Our empirical evidence from the European research project SUddEN (SMEs Undertaking Design of Dynamic Ecosystem Networks) reveals the need for context-sensitive learning support when starting to share and handle business opportunities in a collaborative way. The proposed support system enables partner- and network-specific emergence of situation-sensitive organizational behavior. In meeting user needs we have developed content structures and intertwined interaction features for accurate information exchange. Due to their scalability self-managed, highly structured learning processes are likely to replace prescriptive workflows in continuously changing settings.
\end{abstract}

Keywords: Enterprise Interoperability, Organizational Learning, Collaborative Networks, Topic Maps.

\section{Introduction}

A rapidly changing whilst competitive business environment forces organizations to respond through enterprise transformations on the structural level [1]. One effective way to support transformation processes is to provide representation schemes for conclusive information, such as business processes, as a means for documentation and mutual information exchange [2]. Such an endeavor is even more important in inherently networked organizational settings where business partners and stakeholders collaborate in different locations in an asynchronous way. However, it requires substantial learning effort [3].

In trying to meet these recent challenges several process industries, among them Automotive Industry, started to move from supply chains to supply networks [4]. The production of car parts is getting increasingly complex due to intense pressure from Original Equipment Manufacturers (OEMs). Development and engineering is performed in teams composed of partners from different locations. These teams face demanding requirements with respect to product and process quality, and tight 
production schedules. Moreover, team members are selected with respect to the price of the part to be supplied.

The European research project SUddEN [5] has targeted automotive suppliers in the context described above. The project aimed at the development of a platform supporting knowledge sharing and organizational networking. It should serve teams of suppliers when improving their business performance according to market needs. Basically, it should support collaborative product development and engineering enabling innovative offerings. Guiding this transition from traditional price-based bidding to competence- and network-driven business opportunity handling we have analyzed domain data, elicited requirements of envisioned instruments and tools, and developed a first prototype of such a platform. Based on the evaluation results we could identify a set of features and system architecture required for situation-sensitive collaboration and mutual learning support in supply networks.

In the following, we reflect the research and development process by reviewing the achievements so far. Section 2 reports on eliciting and meeting automotivenetwork requirements. Section 3 details the platform design that could be derived from the outcomes reported in section 2. The most significant findings impacting the platform design concern the structure and representation of content, and the overall flow of control. A particular structure, the Case File, has been introduced as the focal point of collaboration, exchange of information, and learning. The representation scheme of the platform has to reflect polymorphism of content elements, as they have different meaning in different situations. The service-oriented MVC architecture ensures interoperability from the business and application perspective. The resulting adaptability of functionality allows using the platform in various domains. Section 4 concludes the paper wrapping up the results and giving an outlook on future research activities.

\section{Meeting User Requirements for Automotive Networking}

Since we followed a user- and task-centered approach we did not only have to interview and observe networking stakeholders, but we had also to reflect these findings in a hands-on prototype that has been evaluated by the target groups of the envisioned platform for organizational development support.

\subsection{Identifying User Needs}

Working with four networked automotive suppliers in SUddEN (www.SUddEN.org.uk) it turned out organizational learning is mainly triggered by performance measurement (PM). PM is an instrument which provides management information and supports decision making and organizational development [6,7], in particular by reducing a complex system to a set of manageable measures [8]. Performance Measurement has both a systemic and a behavioral aspect. Individual Performance Indicators (PIs) are aggregated and mutually related within a Performance Measurement System (PMS). It allows responsible managers to monitor and assess the performance of a network or overall system along different dimensions. 
As part of organizational learning, the collaborative development and design of a PMS positively influences the performance of the overall collaboration [9]. Among other factors it supports communication and improves coordination, and as such, the operational interoperability among supply network nodes [10].

The SUddEN platform is developed to enable Small and Medium Enterprise (SME) supply networks to improve their performance through competence development (being part of PMS management). The SUddEN prototype allows individual suppliers structuring and recording performance data with respect to competences. A respective questionnaire to acquire data (structures) has been developed by domain experts. Using a generic link mechanism of the platform network members can access information about training and improvement measures addressing various competence dimensions. One innovation in this context is the direct link of individual performance data to the respective results of the comparison with other network members (shown in fig. 1).

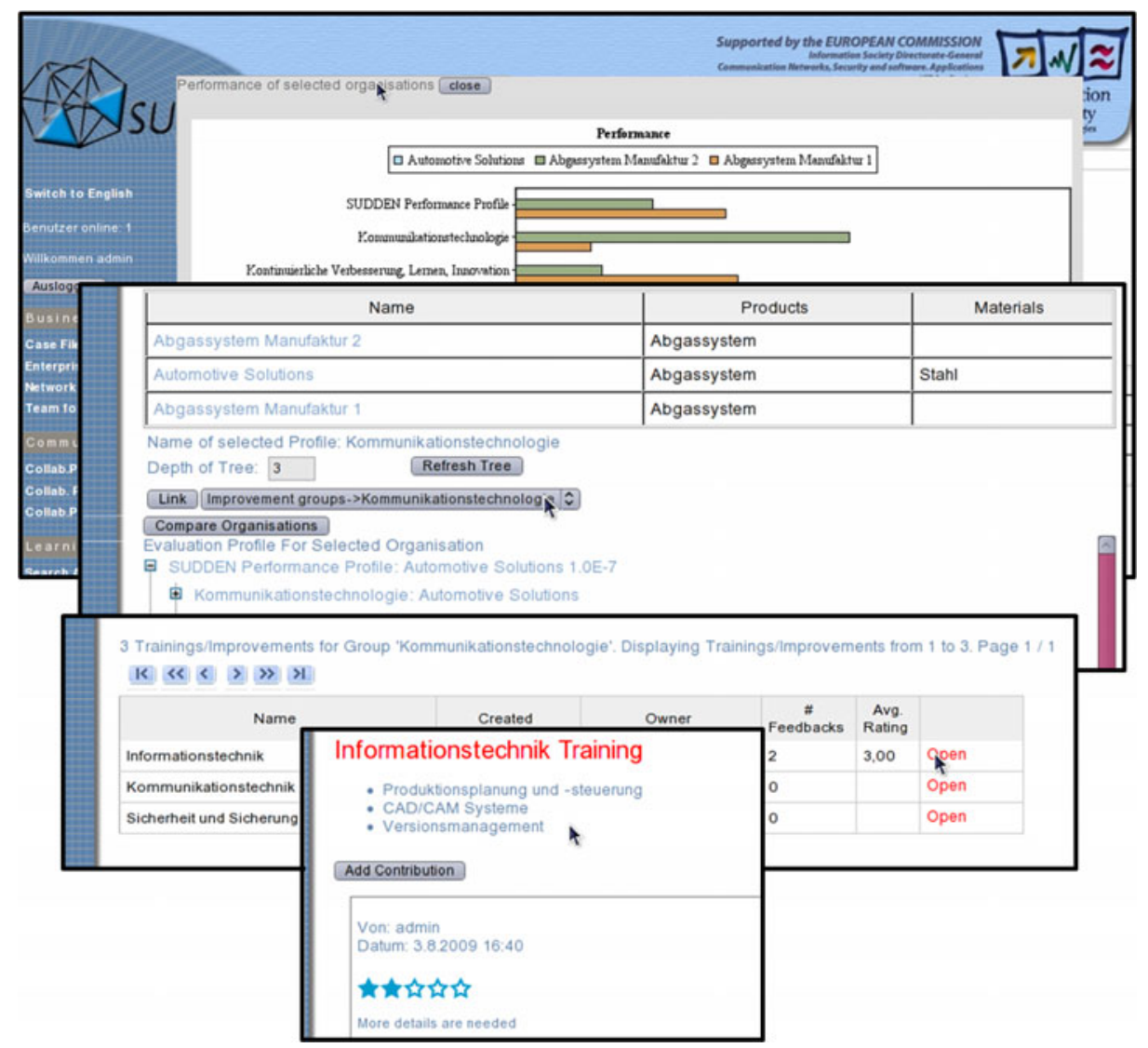

Fig. 1. Performance measurement and comparison of competences intertwined with discussions about a training or measurement for improving the competence dimension 
These data are also linked to communication features on a fine level of granularity, to reflect collectively and learn mutually in a focused dialog. Figure 1 also shows the corresponding user support (bottom window). In the upper window the performance of the user's organization as checked against other suppliers is shown. When selecting a competence dimension of interest and selecting the link to available trainings for improvement the other windows pop up subsequently. Any training can be assessed in terms of effectiveness (using stars) to facilitate discourse and decision making to that respect.

The knowledge base for organizational learning is a (supply) network repository. It contains "Case Files" with relevant and specific information for each business case. A business case starts as business opportunity brought up by a network member, and might end with an innovative process specification to produce a novel (automotive) part. A Case File represents the organizational memory for collective and individual learning processes where product- and process-relevant information is detailed and supplemented over time. Of particular importance for organizational learning ensuring interoperable processes are not only documented results, but rather traceable steps including social interaction, as both are considered relevant for further decision taking.

Communication features like the context-sensitive SUddEN discussion forum allow reflecting and negotiating projects on-line. Network members may link communication entries to content elements, such as performance data, directly. In this way any social interaction becomes part of the Case File, and thus visible to all team members. It might trigger further collaborative learning processes, implementing team learning in a self-organized way.

In organizational learning team members are either involved directly or indirectly in knowledge reflection and generation [11]. Hence, they need to be supported when improving the organization's (and network) performance in the most effective and efficient way. Learning activities become visible through individually handled content items and communication facilities. Once the corresponding features of the platform fit to user needs, stakeholders are likely to actively participate in knowledge generation and transfer (cf. [12]). Of particular importance seems to be the capability of individually linking communication entries to shared content elements (cf. [13]). When working in a collaborative project it is required that on the project level these links can be visualized and shared. This kind of transparency enables users to

- discover novel relationships between information items

- communicate these connections to project team members in a straightforward way

- direct the attention of others to relevant work items or project issues

Experiences from eLearning capturing those scenarios show that knowledge sharing and learning can be facilitated significantly once explicit features can be provided by support platforms (cf. [14]). The meaningful perception of information (domain knowledge) occurs in tandem with establishing communities of learning [15]. The SUddEN prototype encourages users arranging and combining (performance) information as they feel appropriate for the current situation. Content is represented in a 
flexible scheme, in order to allow situation-sensitive arrangement of content elements. For instance, a document might either serve as project report, as data collection or memo, depending on the context and situation of use.

Developing the SUddEN prototype we supported automotive suppliers improving their competence profiles. Individual improvements triggered the performance of network partners and innovative offerings when handling business opportunities. The partners intensively utilized the learning features of the prototype, both, from the perspective of content management based on domain-relevant categories, and the perspective of interaction, linking content elements to communication entries directly to share expertise in a focused way.

\subsection{Evaluating the SUddEN Prototype}

The prototype did not only support performance improvement methodologically, but also allowed hands-on experience of the envisioned learning processes on the individual and network level. We have evaluated the prototype's usability and usefulness through formative and summative evaluation. The results of the usability evaluation using EU-CON II have led to 'hot spots' for further development [16]. The aim of the usefulness evaluation was to finally understand the impact of performance-oriented learning on SME networks. Our intent was to examine to which extent interoperability can be established in large organizational networks.

The usefulness evaluation allowed understanding the prototype support on the operational, tactical and strategic level of interoperability. For each level a focus group has been conducted. For each focus group a questionnaire has been prepared which has been used to guide the discussions among supply network partners. Each group session lasted at least one hour, and has been recorded. In addition, the participants documented the core concepts on paper-cards. In the course of consolidating the findings, these cards have been put into mutual context leading to a concept map. Figure 2 provides a snapshot of the concept map focusing on learning aspects to establish interoperability on all three levels.

Figure 2 depicts the user requirements which have been revisited in the course of evaluation. Encourage innovations indicates that SUddEN supports generating economic viable business cases, facilitating interoperability on the tactical level.

Strengthening suppliers refers to improving the position of the supply industry towards their customers, the Original Equipment Manufacturers (OEM). The element strengthening one's abilities/learning refers to the individual organization or team of suppliers working on a project.

Communication functionality has been provided in the SUddEN prototype through a number of features. One key element is supporting presentation of ongoing work through the network repository in terms of performance competencies. Team members collaborating in an innovation project can trace decision making procedures and the current state of the project. Fundamental to this feature is the polymorph representation of content, as information items might have different meaning in different contexts. 


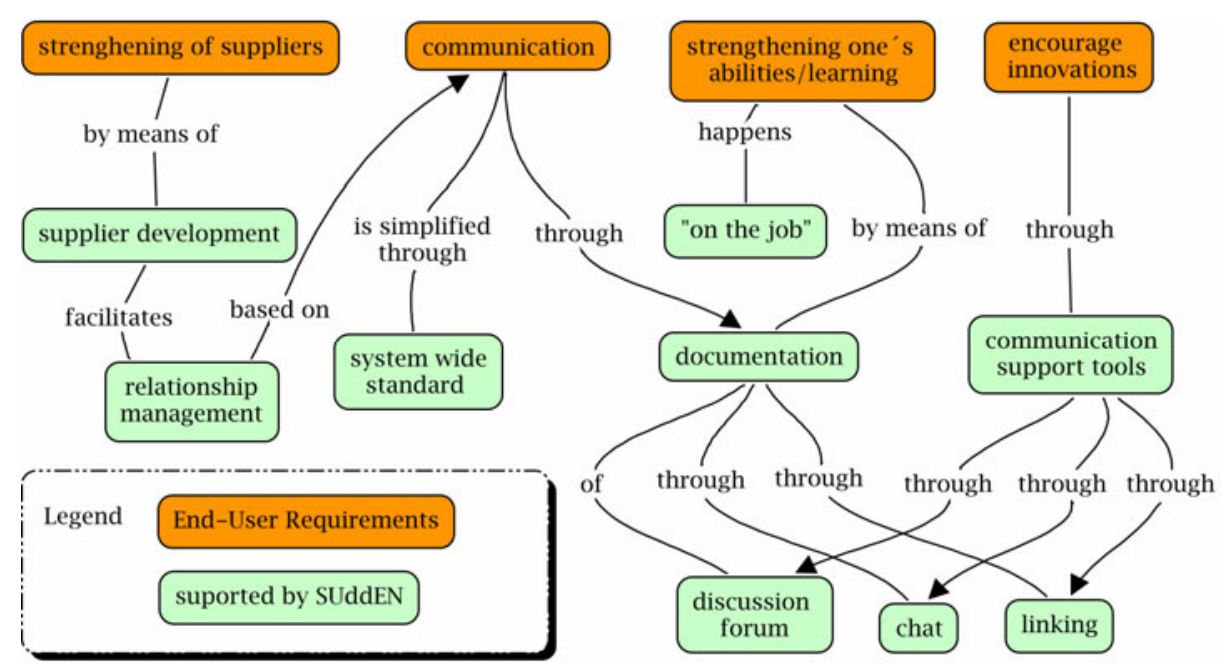

Fig. 2. Functionalities of SUddEN identified by end-users meeting their requirements with respect to learning and development

Interestingly, in the course of evaluation participants did explicitly not distinguish communication from learning. Learning is considered as exchange of relevant information. While working on a project some users contribute information relevant to other team members according to their functional role. Users communicate requirements to the overall team by providing this information. In another example, a sub-team discusses relevant team matters in a discussion forum. The results of this discussion become available through the Case File to the overall team. Thus, content creation is of equal importance to communication. Typically, the documentation of supplier development measures is an inherent part of a discussion - enabled through the SUddEN generic mechanism linking communication entries to fine-grain content elements (see above).

Due to market requirements in the Automotive Industry learning has to occur in a collaborative, but mainly self-organized manner, once a business opportunity is provided as input by the network coordinator. When dealing with innovation the respective projects are characterized by the gradual specification of the innovation through multiple team members. In order to ensure organizational interoperability, all generated content needs to be stored in a central repository. We will reflect these requirements in the next section, by discussing the representation scheme required for organizational interoperability, and the arrangement of features along services (relevant on the operational and tactical layer).

\section{Platform Design}

After revisiting the user requirements through evaluating hands-on prototyping, we can come up with a conceptual design of a platform supporting dynamic collaborative supply networks. An organizational learning platform of this kind needs a representation 
infrastructure allowing polymorph content and communication representation, as described in section 3.1. It also requires a modular and service-oriented architecture, as introduced in section 3.2.

\subsection{Polymorph Content Representation}

The flexible representation scheme has to allow keep content elements and link structures (including the addressed coupling of content elements to communication entries) according to their context of use. It is required to enable (i) representing different types of content, (ii) storing content elements in different, arbitrary forms of representation, (iii) adding individual information and remarks to content elements, (iv) mutually relating content elements, (v) attaching structural and domain-specific meta-data to content elements [17].

Topic Map technologies meet these requirements, as already demonstrated in the context of eLearning applications (cf. [18][19][20]). In SUddEN, Topic Maps allow team members to flexibly structure content according to their needs as well as linking content to social interventions, such as communication entries of a forum.

A topic map basically consists of topics, associations, occurrences, and scopes. Topics are the fundamental element of a topic map. They represent subjects of the perceived world (represented in a map). The relationship between topics and subjects therefore corresponds to the one between representation and referent in the semiotic thetrahedron (cf. [21]).

Associations represent relationships between subjects and, accordingly, are used to mutually relate the topics representing these subjects. Each end point of an association has to be defined in an association role. These roles are taken by connected topics. Association roles therefore represent the involvement of a subject in a relationship [23].

Occurrences are the links to the 'outer world' (outside the topic map) and complete the expressiveness of the topic map concept by adding index functionality. An occurrence is a representation of a relationship between a subject and an information resource [23].

Scopes are a means to define the contexts in which certain statements of a topic map are valid. Occurrences and associations are such statements. They can be used to describe domains captured by a topic map.

In this way Topic Maps provide inherent functionality to operate SUddEN on a flexible data model. In particular, it allows handling content elements and communication entries in the same way, while still allowing provision of meta data, as for categorizing content elements.

In fig. 3 a topic map example representing a performance measurement system (PMS) for a "Business Opportunity (BO-17)" is shown. It aggregates, using a weighted sum function, two competence dimensions - "Quality Management (QM)" and "Fault Parts". These dimensions are in a certain role, representing the weights used. The competence dimension "Fault Parts" has different occurrences in different scopes, to allow representing context-specific values - company A (2ppm) and B (6ppm). 


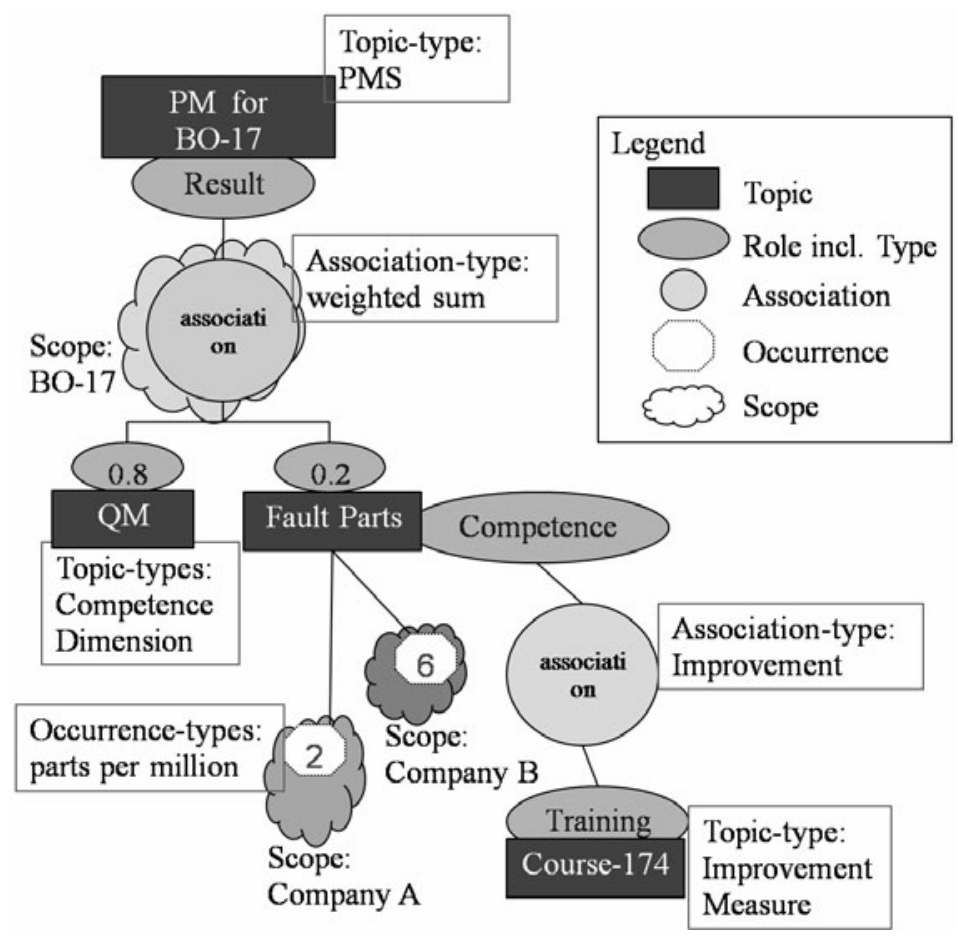

Fig. 3. Topic Map representing performance measurement systems

Each competence (dimension) is additionally associated with possible measures that a company may take to improve its performance.

\subsection{Architecture}

The overall architecture follows a modular Model-View-Controller approach. In fig. 4 the software packages are specified taking into account the MVC pattern. The platform is developed utilizing the Spring Framework [24], since it supports objectoriented programming principles and fosters the integration of different application APIs. Moreover, the framework is non-intrusive, as it allows developing the business logic without dependencies to Spring-specific classes.

Modules expose functionality through services. Each module is implemented following the Model-View-Controller pattern (shown on the vertical axis in figure 4). The View part of a module provides code for the web-based user interface implemented conform to the Java Server Faces (JSF) framework standard. The View part is tightly coupled with a Controller component, providing server-side Java code. A Controller facilitates access for the View to the business logic and the Model in general. 


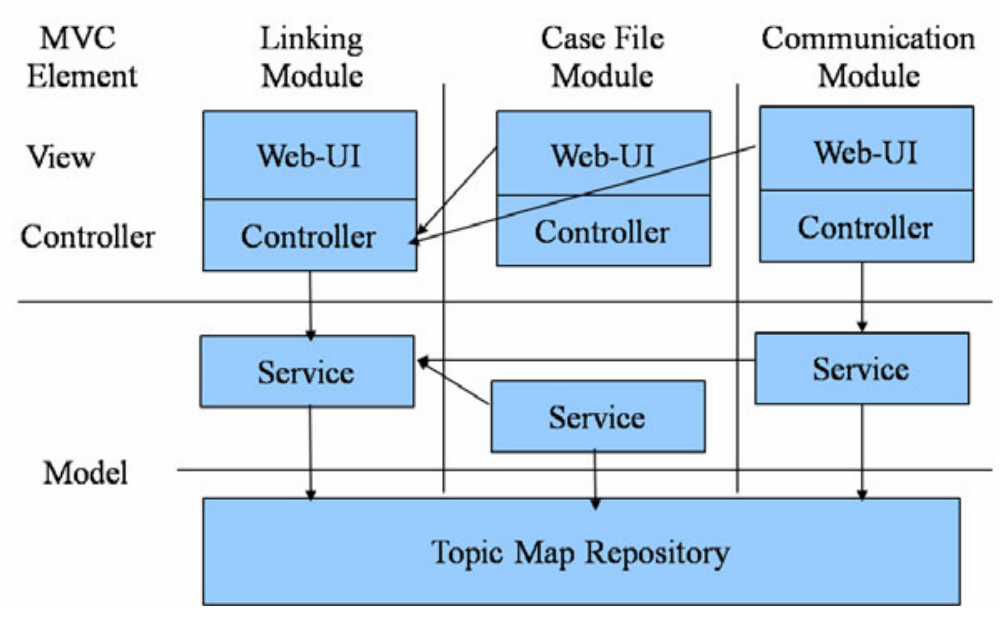

Fig. 4. Platform Architecture

The link module is of particular importance. It allows users to place links between topics, and is written in a generic manner. Services that are target or source of a link need to implement a certain interface. When implementing a module as a source for a link, developers have to include the link Controller within their User Interface JSF files. A button is used to trigger the dialog for selecting the link target. Modules which are targets of links, need to be registered using a Spring-managed configuration file. In this way the dialog of the link module can provide a list of accessible modules.

\subsection{Learning Support}

The SUddEN approach provides support for learning 'on-the-spot', as suppliers interpret their performance data always in a certain context. Topic Map occurrences represent performance data specific to business opportunities. Links attached to competence dimensions guide users to identify measures for improvement. They might be challenged and discussed with respect to their suitability given a certain situation. Since all proposals and modifications of performance data are stored, SUddEN ensures utmost transparency of effects when setting a particular measurement.

SUddEN also supports learning from prior business cases. Supply network performance and PMS changes, decisions and improvement measures are kept for each business case, and can be reviewed from the content and communication perspective. Closed Case Files provide insights into past experiences, and allow team members to improve mutual interaction and the process of decision taking.

The latter is of crucial importance, as it addresses organizational interoperability. Using SUddEN the interoperability between network partners, applications, or domains can be improved, since business opportunities and cases are handled in relation to the organizations involved, including particularities organizing their work. The 
processed and shared performance data, decision making procedures and measurements are made transparent, reducing the effort of future decision taking.

\section{Conclusion}

As supply chains are developed to supply networks, novel forms of learning support gain momentum. Network partners need to re-team to come up with innovative offerings to customers. Such dynamic collaborative mechanisms between SMEs can be found within the Automotive Industry. They require flexibility regarding content structures as well as closely tuned social interactions. The presented SUddEN approach is a European effort to promote semantic interoperability on several organizational network layers by means of focused learning processes.

A generic representation scheme allows for openness regarding content structure and communication, inherent to learning and/or innovation processes. The features of the platform support learning through individualizing content and communication when handling a business opportunity and developing a business case in the network. Collaboration includes individual and group development/improvement opportunities of performance in terms of competences. In this sense, SUddEN triggers the alignment of networked processes 'on-the-job', as concrete cases lead to the construction of envisioned solutions in a team. Interoperability is the target while working on a business case. It develops through understanding others. Since all learning steps are kept in a context-sensitive repository, innovations and decisions can be traced in the course of reflection and for designing further developments.

\section{References}

1. Stephenson, St.V., Sage, A.: Architecting for Enterprise Resource Planning. Information Knowledge Systems Management 6, 81-121 (2007)

2. Rouse, W.B. (ed.): Enterprise Transformation: Understanding and enabling Fundamental Change. Wiley, Hoboken (2006)

3. Brown, J., Duguid, P.: Organizing Knowledge. Reflections, Society of Organizational Learning 1(2) (1999)

4. ENSR Consortium, 2003 Observatory of European SMEs -Part 5: SMEs and Cooperation, European Network for SME Research (ENSR), European Communities (2004)

5. Weichhart, G., Feiner, T., Stary, C.: Implementing Organisational Interoperability - The SUddEN Approach. Computers in Industry 61(2), 152-160 (2010)

6. Schmitz, J., Platts, K.: Supplier Logistics Performance Measurement: Indications from a Study in the Automotive Industry. International Journal of Production Economics 89, 231243 (2004)

7. Zäpfel, G., Piekarz, B.: Wirkungskettenorientiertes Performance Measurement für Supply Chains. In: Seicht, G. (ed.) Jahrbuch für Controlling und Rechnungswesen, pp. 377-411. LexisNexisORAC Verlag (2003)

8. Perrin, B.: Effective Use and Misuse of Performance Measurement. American Journal on Evaluation 19(3), 367-379 (1998) 
9. Thrane, S., Hald, K.S.: The Emergence of Boundaries and Accounting in Supply Fields: The Dynamics of Integration and Fragmentation. Management Accounting Research 17, 288-314 (2006)

10. Lohman, C., Fortuin, L., Wouters, M.: Designing a Performance Measurement System: A Case Study. European Journal of Operational Research 156, 267-286 (2004)

11. Kim, D.: A Framework and Methodology for Linking Individual and Organizational Learning: Applications in TQM and Product Development, PhD Thesis, Sloan School of Management, Massachusetts Institute of Technology (1993)

12. Schulmeister, R.: Grundlagen hypermedialer Lernsysteme. Theorie- Didaktik- Design. Addison Wesley, Bonn (1996)

13. Kienle, A., Herrmann, T.: Integration von Kommunikation und Kooperation an Hand von Lernmaterial - ein Leitbild für die Funktionalität kollaborativer Lernumgebungen. In: Proc. Mensch \& Computer 2002, GI \& ACM German Chapter, Teubner, Stuttgart, pp. 45 $54(2002)$

14. Auinger, A.: Didaktikgeleiteter Wissenstransfer. Deutscher Universitätsverlag, Wiesbaden (2005)

15. Stary, C.: Content als Kontext zur Kommunikation im e-learning. eLearning, vol. 1(1). Studienverlag (2006)

16. Stary, C., Riesenecker-Caba, T.: EU-CON II -Software-ergonomische Bewertung und Gestaltung von Bildschirmarbeit. Wirtschaftsverlag NW, Dortmund (1999)

17. Oppl, S.: Flexibility of Content for Organisational Learning. Master's Thesis. Johannes Kepler University Linz (2007)

18. Dicheva, D., Dichev, C.: TM4L: Creating and Browsing Educational Topic Maps. British Journal of Educational Technology - BJET 31(3), 391-404 (2006)

19. Matsuura, S., Naito, M.: Creating a Topic Map Based e-Learning System on Introductory Physics. In: Maicher, L., Garshol, L.M. (eds.) TMRA 2008, pp. 247-260 (2008)

20. Schmiech, M.: Didaktische Ontologien zur Organisation digitaler Objekte in der Arbeit von Lehrkräften, http://www.zhb-flensburg.de/dissert/schmiech/ Schmiech $202006 \% 20-\% 20$ Didaktische 200 ntologien $\% 20$ zur\% 200 rganisation\%20digitaler $\% 200 b j$ ekte $\% 20$ in 20 der 20 AvL . pdf (2006)

21. Vatant, B.: Ontology-driven Topic Maps. In: Proc. of XML Europe 2004, Amsterdam (2004)

22. Falkenberg, E.D., Hesse, W., Lindgreen, P., Nilsson, B.E., Oei, J.L.H., Rolland, C., Stamper, R.K., van Assche, F.J.M., Verrijn-Stuart, A.A., Voss, K.: A Framework of Information System Concepts. The FRISCO Report. online version, International Federation for Information Processing WG 8.1 (1998)

23. ISO JTC1/SC34/WG3: Information Technology - Topic Maps - Part 2: Data Model. International Standard 13250-2, ISO/IEC (2006)

24. Wolff, E.: Spring 2: Framework für die Java-Entwicklung, 2nd edn. Dpunkt. Verlag (2007) 